\title{
Mutual Competitive Absorption of Water and Essential Oils Molecules by Porose Ligno-Cellulosic Materials
}

\author{
Břetislav Češek, Miloslav Milichovský, Jan Gojný \\ Institute of Chemistry and Technology of Macromolecular Materials, Department of Wood, Pulp and Paper, \\ Faculty of Chemical Technology, University of Pardubice, Pardubice, Czech Republic \\ Email: Bretislav.Cesek@upce.cz
}

Received 28 January 2014; revised 1 March 2014; accepted 15 March 2014

Copyright (C) 2014 by authors and Scientific Research Publishing Inc.

This work is licensed under the Creative Commons Attribution International License (CC BY). http://creativecommons.org/licenses/by/4.0/

(c) (i) Open Access

\begin{abstract}
Competitive absorption processes, i.e. condensation, of water and essential oils (EO) are predominantly controlled by extent of condensation of diffusing water and EO molecules with marginal influence of porose ligno-cellulosic matter and a sort of EO. With increase of absorption the diffusion is depressed and vice versa. Diffusion of water molecules through porose system is usually slower in comparison with other molecules. It was discovered that a presence of EO decreases paper web humidity with increasing influence in environment with high relative air humidity. Likely, fast diffusing EO molecules decrease the ability of water molecules condensed in all accessible pores particularly in the non-penetrable pores.
\end{abstract}

\section{Keywords}

Cellulosic Base Materials; Essential Oils; Moistening; Porous Materials; Vapour Absorption

\section{Introduction}

Terms as recycling, secondary fibres, paper recovery, preservation and conservation of culture heritage on wood and paper basis etc. are connected with aging of ligno-cellulosic materials like paper and other cellulosic products. In this context, a use of natural products as essential oils (EO) plays an increasing role in having antimicrobial activity (bactericidal, fungicidal and sporicidal effects) [1]-[3] and reducing wet-ability of ligno- cellulosic materials.

Typical for paper and similar ligno-cellulosic materials is a porous non-oriented hypermolecular structure. Due to this structure and hydrophilic surface-molecular character of pore interface, ability to humidification with 
characteristic water vapour absorption kinetic [4] is typical for these materials. A lot of biomaterials applications especially a tremendous potential for biomedical applications and drug delivery systems are connected with water vapour and other liquid vapour absorption [5] [6]. Surprisingly, no information exists about mechanism of these processes especially the competitive water vapour, and other vapours absorption processes are missing. A lack of information about behaviour of EO in ligno-cellulosic materials is typical. No knowledge exists in sorption EO. Especially, the knowledge of mutual behaviour of water and essential oil molecules in pores of ligno-cellulosic materials is important.

The amount of absorbed water (likewise EO), and the velocity of this process are dependent on a lot of factors [7]. Except temperature, partial pressure of EO and relative humidity of air vicinity, the parameters as fibre components, degree of fibre beating, composition and amount of further fillers, degree of sizing and other auxiliary paper agent's presence are important too. The porosity of paper material and its structure combined with the properties of pore interfaces appear to be the most important properties influencing hygroscopicity and EO absorptivity. Generally, vapour absorption of water and other liquids in porous materials is given by their microstructure and hypermolecular properties. It was shown [4] that the kinetics of important practical absorption vapour processes as vapour condensation and moistening of porous web material can be described using of relative simple function.

\section{Theoretical Part}

It was demonstrated that the kinetics of paper and of the moulded fibre products moistening or one component vapour absorption of organic liquids is satisfactory described by the following originally empirical later theoretically derived and experimentally verified Equation (1):

$$
\Delta Y=\frac{a t^{d}}{b+t^{d}}
$$

where:

- $\Delta Y\left(=Y-Y_{\mathrm{i}}\right)$ is increment of moisture content (mass of liquid per unit mass of dry solid), given as the difference between current moisture content, $Y$, and initial moisture content at the beginning of the experiment, $Y_{\mathrm{i}}$ or by use of moisture of sample $y(w / w)$ according to recalculation $Y=y /(1-y)$;

- $t$ is the time (in days) of sample storage at a given relative air humidity;

- $d$ characterises the rate of steady-state adjustment, $a\left(=\Delta Y_{\mathrm{e}}\right)$ is the hygroscopicity or absorption capacity of the porous materials and parameter $b\left(\right.$ day $\left.^{\mathrm{d}}\right)$ is:

$$
b=x_{r a}^{2} \phi /\left(d D_{a p} \Delta Y_{e}\right)
$$

The steady-state moisture or steady-state absorption capacity of porose flat sample, $Y_{\mathrm{e}}$, is given as $Y_{\mathrm{e}}=a+Y_{\mathrm{i}}$. If $d>1$ or $d<1$, the porous web material of sample thickness ( $2 x_{\text {ra }}$ ), has stratified structure with worse uniformity where vapour diffusion takes place slowly or rapidly than in an ideal web porous material, respectively, that is, the sample uniformity decreases.

Apparent or pseudo-diffusion coefficient:

$$
D_{a p}=D_{a p}^{1} / d
$$

where:

$$
D_{a p}^{1}=\phi x_{r a}^{2} / b \Delta Y_{e}
$$

is hence proportional to a given relative air humidity, $\varphi$. For better comparison of diffusivity results we have been relativized these coefficients with apparent diffusion coefficient of pure water at comparable conditions according to Equation (2), defined as $D_{\text {rel }}=D_{\text {ap }} / D_{\text {ap }}\left(\mathrm{H}_{2} \mathrm{O}\right)$, i.e. a ratio of $D_{\mathrm{ap}}$ of water or EO vapours during a common absorption process at given relative air humidity (R.H.) to the apparent diffusion coefficient of pure water at given R.H., $D_{\mathrm{ap}}\left(\mathrm{H}_{2} \mathrm{O}\right)$.

$$
D_{r e l}=\frac{(b \cdot a \cdot d) \text { pure water vapour at given R.H. }}{(b \cdot a \cdot d) \text { water or EO vapours at given R.H. }}
$$

The process of vapour condensation, i.e., vapour absorption, in porous web material takes place hence by dif- 
fusion of vapour from surrounding atmosphere into pores of porous flat medium following by quick condensation in suitable pores. The suitable pores are all pores which size characterized by equivalent cylindrical pore radius $r \leq r(\varphi)$. The value of maximal equivalent cylindrical pore radius, $r(\varphi)$, occupied by the condensed liquid, e.g., water in the pore material at constant temperature and relative humidity, is expressed by the well-known Kelvin equation.

During experiments weight increments of all condensed components are monitored gravimetrically, i.e. the Equation (1) is then written generally in the form (3).

$$
\Delta Y=\sum_{i=1}^{i=n} \frac{a_{i} t^{d}}{b_{i}+t^{d}}
$$

where $a_{\mathrm{i}}$ and $b_{\mathrm{i}}$ are the absorption capacity and coefficient of i's component absorbed in the porous materials, respectively. Supposing behaviour of the multicomponent EO vapour as one component, two components' the vapour of water and EO is given hence by Equation (4).

$$
\Delta Y=\frac{a_{\phi}(E O) t^{d}}{b_{1}(E O)+t^{d}}+\frac{a_{\phi}\left(\mathrm{H}_{2} \mathrm{O}\right) t^{d}}{b_{2}\left(\mathrm{H}_{2} \mathrm{O}\right)+t^{d}}
$$

Relative simple experiments enable so us to evaluate a mechanism of all absorption processes taking place in porose the ligno-cellulosic materials in flat form. To receive a full knowledge of common absorption of water and EO vapours is necessary to measure gravimetrically a kinetic of weight increment of web sample during absorption of:

1) pure water vapour;

2) common water and EO vapours.

The absorption capacities and diffusivities of water and EO are then received by following data verification by help of Equation (1) and Equation (4), respectively.

\section{Experimental Methods}

\subsection{Materials}

1) Handsheets of paperboard weighing $400 \pm 15 \mathrm{~g} \cdot \mathrm{m}^{-2}$ prepared from following composition:

- DM (virgin groundwood) consisting of $90 \%$ of the groundwood (beating degree according to Schopper-Riegler (SR) equal to 60) and 10\% of MgBi-sulphite spruce bleached pulp (SR 25);

- Sa J (bleached sulphate softwood pulp), SR 25;

- Sa L (bleached sulphate hardwood pulp), SR 25;

- Si (MgBi-sulphite spruce bleached pulp), SR 25.

After defibration in a laboratory hollander beater, the sample sheets were formed according to the ISO 5269-2 standard. A method of molecular groping of pores has been used to characterization of hypermolecular structure and surface-molecular properties of pore interface of paperboard samples. The method is based upon controlled humidification and vapour absorption of selected organic substances (toluene and methyl-ethyl ketone) in porose non-structuralised flat material. All samples were acclimatised before the start of experiment for 10 days in the desiccator filled with dry silicagel at room temperature $(23 \pm 1)^{\circ} \mathrm{C}$. At least three values measured were averaged to give a mean value reported in this paper.

2) Selected essential oils (EO) showing the best microbicidal effects were assessed:

- Lavender (Lavandula species);

- Lime (Citrus aurantifolia);

- Myrtle (Myrtus communis);

- Cinnamon (Cinnamomum zeylancium);

- Juniper Berry (Juniperus communis);

- Citronella (Cymbopogon nardus).

The concentrated oils purchased from a dealer were not added into the medium but dripped on open the Petri dishes in amount approximately $2 \mathrm{ml}$ of EO per desiccator.

\subsection{Used Methods}

The kinetic of mutual competitive absorption of water and essential oils by porose ligno-cellulosic materials 
were measured by use of two gravimetric methods. The test methods were represented by simple desiccator method (non-controlled, i.e. worse controlled condition) and by special designed box method (controlled condition). All measurements were carried out at a temperature of $23 \pm 1^{\circ} \mathrm{C}$ and relative air humidity of $50 \pm 5 \%$ with paper strip samples. These strips were conditioned 10 days in the desiccator filled with dry silicagel. The strips with constant width of $15 \mathrm{~mm}$ were cut from the handsheets and everyone was put in a weighing bottle cell with open lid being closed before weighing in case of desiccator method. In case of box method the strips were weighed directly. The samples were then exposed to the common influence of water and EO vapours. At the bottom of the glass desiccators and the testing box were inserted evaporating dish with $2 \mathrm{ml}$ of EO and container with solution of salt that corresponds to the desired relative humidity. The relative humidity in both of testing devices equal to $49 \%, 75 \%$ and $97 \%$ has been achieved by means of saturated solution of $\mathrm{KNO}_{2}, \mathrm{NaCl}$ and $\mathrm{K}_{2} \mathrm{SO}_{4}$, respectively. As reference, a blend experiments were realised hence with only pure water atmosphere at $49 \%, 75 \%$ and $97 \%$ of relative humidity.

Experimental conditions of the absorption processes are limited only by strictly safe of diffusion vapour process without any various movement of atmosphere in a glass weighing bottle cell. At least two values measured were averaged to give a mean value reported in this paper. All received data were evaluated by use of theoretical relations (1) and (4) (e.g. see Figure 1). By help of the equations (1) and (4) were evaluated then the absorption capacities for both water and essential oils (EO) components especially $a_{49}(\mathrm{EO})$ and $a_{97}(\mathrm{EO})$, i.e. absorption capacities of EO vapours at $49 \%$ and $97 \%$ R.H., respectively, and both the diffusion parameters:

- $D_{\text {1rel }}(\mathrm{EO})$ - relative diffusion coefficient of EO;

- $D_{2 \text { rel }}\left(\mathrm{H}_{2} \mathrm{O}\right)$ - relative diffusion coefficient of water.

Both parameters compared with apparent diffusion coefficient of pure water at comparable conditions (i.e. R.H. and kind of EO and paperboard). The received results are summarised in Table 1 and Table 2. Results are an average of duplicates with less than $8 \%$ deviation between samples.

\section{Results and Discussion}

As follows from Table 1, porosity of paperboard from groundwood (DM) representing a high yield wood pulp is distinctly highest with hydrophobic character of pore interface compared with the tested low yield bleached pulps. This fact is appeared in worse of DM wettability as demonstrated lower values of its adhesion tension $\left(\sigma_{T}\right)$, surface tension $\left(\gamma_{s}\right)$ and the highest value of relative dispersion component of surface tension $(d)$. For all that, the paperboard containing of groundwood (DM) is distinguished by the highest saturated humidity $\left(Y_{\mathrm{e}}\right)$ achieved at all R.H., because lower size of its pores. Differences among bleached sulphate and sulphite pulps as well as long-fibred and short-fibred pulps are small. Typical for all of these bleached pulps is a high their hydrophilicity. Highest saturated humidity $\left(Y_{\mathrm{e}}\right.$ ) prove the paperboard prepared of short-fibred bleached hardwood pulp (Sa L), because theirs the high relative porosity and the smaller pores. However, common for all tested pulps is their anionactive character of polar hydrophilic part of surface tension-higher in case of bleached pulps (compare the parameters $\gamma^{-}$and $p^{-}$). Additionally, data characterised of wet hypermolecular structure of used pulps (see Table 2) support very well these observations. Due to higher hydrophilicity of bleached pulps water vapour condensed in higher amount and in the bigger pores than in the groundwood samples.

Received results confirmed that both the absorption capacity and diffusivity of EO in porose non-structuralised material as paper are not constant at different relative humidity. Thought absorption and diffusion of both the EO and water vapours molecules are influenced by the sort of porose non-structuralised ligno-cellulosic material and EO, the both absorption capacity and diffusivity of molecules are independent and deciding factors but mutually influenced variables. The absorption process itself is given by condensation of water vapour and EO molecules in appropriate pores. However, as received results indicate, competition of two physical-chemical phenomena is responsible for all process:

- a competition of diffusivity vs. molecular absorbability;

- a competition of water vs. EO molecules.

These two phenomena are intimately connected. Due to competition of EO molecules with water molecules the whole absorption process is more complicated. At comparable molecular affinity of both sort of molecules to surface pore walls, the molecules with higher diffusivity are preferred in sorption, i.e. a race is win by the more free molecules at comparable affinity. As indicated in Figure 2, a decision role plays sorption ability of compete molecules. It is generally true that the higher the absorption of molecules is the lower is their diffusivity, e.g. 


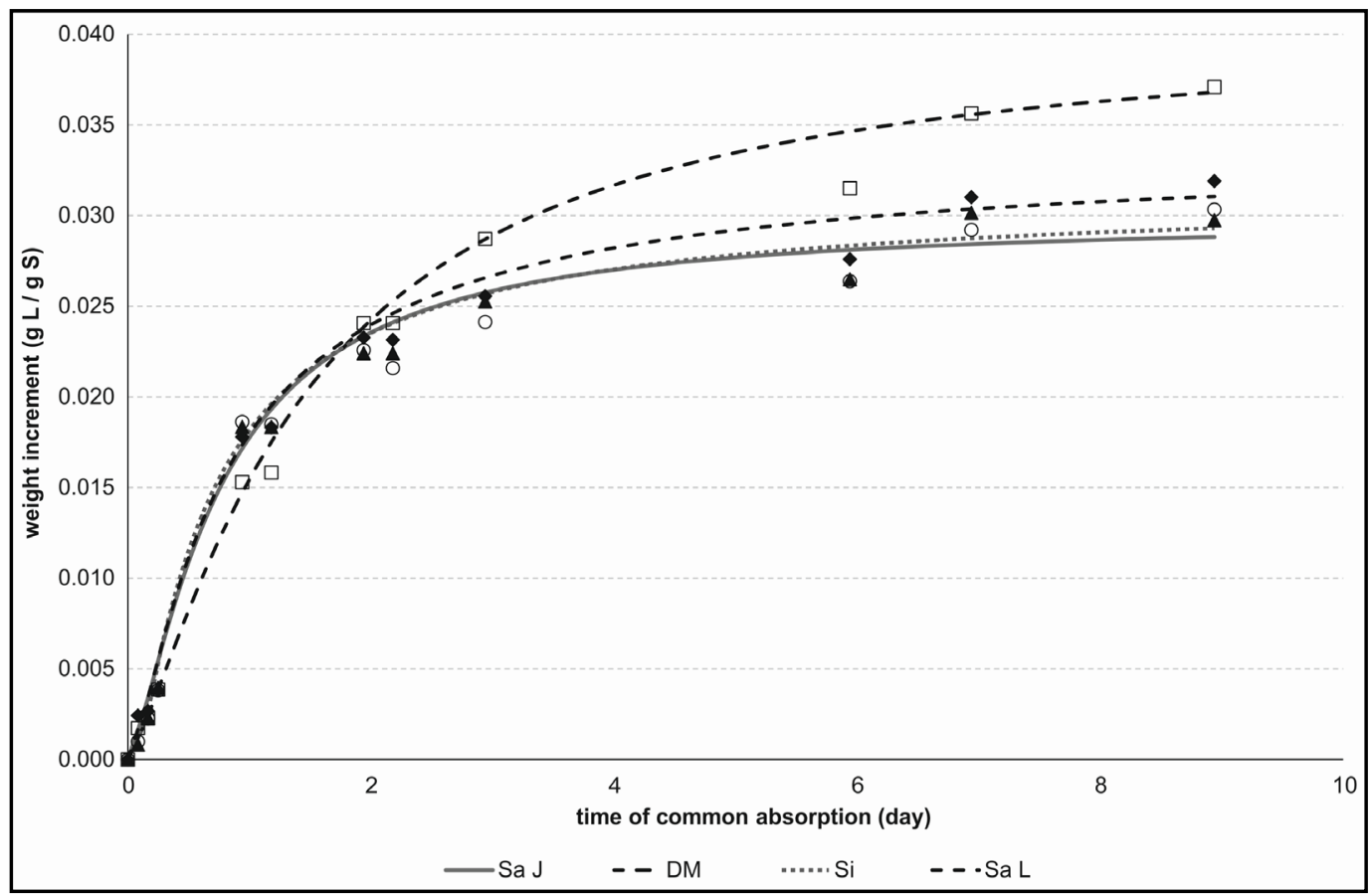

Figure 1. Weight increment time dependence during common humidification and lavender vapour absorption process for paper web of different composition. Relative air humidity is $75 \%$.

Table 1. Characterisation of hypermolecular structure and surface-molecular properties of pore interface of used paperboard samples..

\begin{tabular}{|c|c|c|c|c|}
\hline & DM & Sa J & Sa L & $\mathrm{Si}$ \\
\hline Apparent density, $\mathrm{kg} \cdot \mathrm{m}^{-3}$ & 442.73 & 643.26 & 581.05 & 708.55 \\
\hline$\varepsilon, \%$ & 71.6 & 59.29 & 63.2 & 55.2 \\
\hline "Effective mean pore, $\mu \mathrm{m}$ & 2.3 & 6.8 & 4.9 & 4.7 \\
\hline${ }^{*}$ Dispersiveness of pore distribution, $\mu \mathrm{m}$ & 3.4 & 26 & 10 & 12 \\
\hline$\sigma_{\mathrm{T}}, \mathrm{mN} / \mathrm{m}$ & 2.6 & 7.5 & 6.1 & 5.7 \\
\hline$\gamma_{\mathrm{s}}, \mathrm{mN} / \mathrm{m}$ & 33.2 & 33.7 & 33.5 & 33.5 \\
\hline$\gamma_{\mathrm{d}}, \mathrm{mN} / \mathrm{m}$ & 30.1 & 30.1 & 30.1 & 30.1 \\
\hline$\gamma^{+}, \mathrm{mN} / \mathrm{m}$ & 0.28 & 0.28 & 0.28 & 0.28 \\
\hline$\gamma^{-}, \mathrm{mN} / \mathrm{m}$ & 8.6 & 11.6 & 10.7 & 10.5 \\
\hline$\gamma_{\mathrm{p}}, \mathrm{mN} / \mathrm{m}$ & 3.1 & 3.6 & 3.5 & 3.4 \\
\hline$d$ & 0.91 & 0.89 & 0.90 & 0.90 \\
\hline$p$ & 0.09 & 0.11 & 0.10 & 0.10 \\
\hline$p^{+}$ & 0.01 & 0.01 & 0.01 & 0.01 \\
\hline$p^{-}$ & 0.26 & 0.34 & 0.32 & 0.31 \\
\hline$Y_{\mathrm{e}}(97 \%),(\mathrm{g} L / \mathrm{g} S)$ & 0.29 & 0.22 & 0.26 & 0.24 \\
\hline$Y_{\mathrm{e}}(75 \%),(\mathrm{g} L / \mathrm{g} S)$ & 0.11 & 0.08 & 0.09 & 0.08 \\
\hline$Y_{\mathrm{e}}(49 \%),(\mathrm{g} L / \mathrm{g} S)$ & 0.06 & 0.05 & 0.05 & 0.05 \\
\hline
\end{tabular}

Remark: "Effective mean pore diameter and pore size dispersiveness provided that pore size distribution function is controlled by theoretical Gauss distribution.

with an increase of EO absorption a relative diffusivity of its molecules decrease independent of all other factors. Logically, an increasing of absorption retards the diffusivity of molecules [4].

As indicated Figure 3, an absorption capacity of water vapour for all pulp sorts is increased exponentially with increase of relative air humidity being influenced in small extent by pulp quality and presence of EO 
Table 2. Characterisation of wet hypermolecular structure of used paperboard samples.

\begin{tabular}{ccccc}
\hline & DM & Sa J & Sa L & Si \\
\hline$\varepsilon_{i}(49 \%), \%$ & 2.76 & 3.34 & 3.07 & 3.67 \\
$\varepsilon_{j}(75 \%), \%$ & 4.80 & 5.21 & 5.27 & 5.88 \\
$\varepsilon_{k}(97 \%), \%$ & 12.78 & 13.73 & 15.19 & 16.57 \\
${ }^{*} i,(\mu \mathrm{m})$ & 0.2 & 0.6 & 0.5 & 0.5 \\
${ }^{*} j,(\mu \mathrm{m})$ & 0.5 & 1.5 & 1.2 & 1.2 \\
${ }^{*} k,(\mu \mathrm{m})$ & 5.1 & 14.3 & 11.7 & 11.0 \\
\hline
\end{tabular}

Remark: " $(i, j, k)$ Effective maximal pore diameter (smaller pores inclusive), fulfilled with condensed water at R.H. 49\%, 75\% and 97\%, respectively.

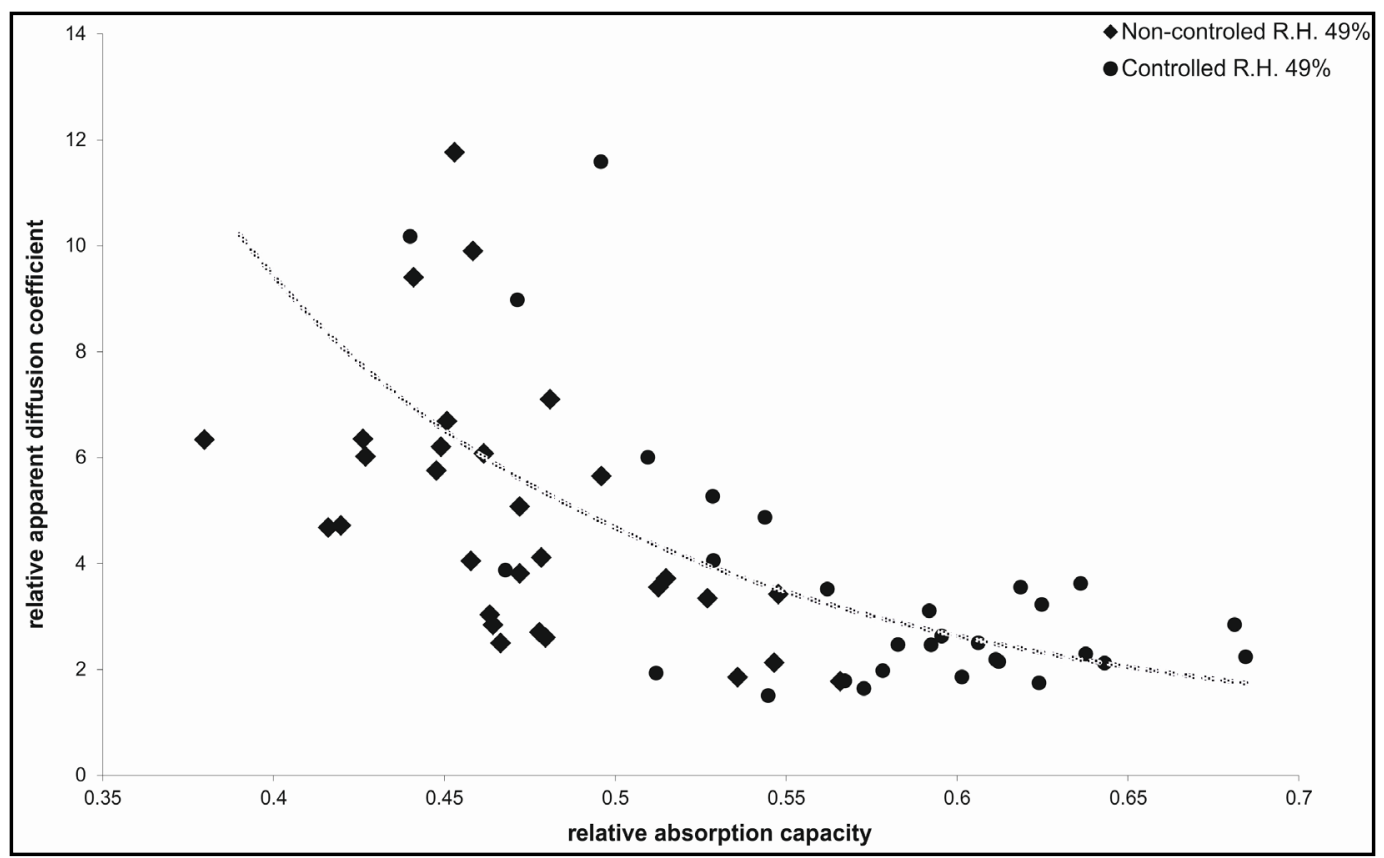

Figure 2. Dependence of relative apparent diffusion coefficients vs. relative absorption capacities of water and the EO vapour for all sorts of searched ligno-cellulosic materials.

molecules. Compared with pure water, the absorption capacity of EO in porose (non-structuralised) material as paper is also not constant at different R.H. and with increasing of R.H. increases as well as but relatively in more small extent. Further, the absorption capacity of water vapour is markedly higher for absorption from pure humid atmosphere compared with polluted environment, e.g. by EO. Moreover, it was observed as well that mostly water absorption in pure water vapour environment exceeds a sum of absorbed components in composed atomsphere inclusive water vapour.

Though total the absorbed amount of all components is lower in comparison with pure water, the process is than resulted not only by decrease of absorption water capacity but controversially even by small increase of EO absorption capacity (see Figure 3). A relative absorption increase of EO vapour is accompanied than by relative decrease of its diffusivity. On other hand, obviously, with increasing of relative water and EO molecules diffusivities (compared with apparent diffusion coefficient of water itself at comparable conditions) the absorption capacity ratio of EO is increased proportionally, i.e. the absorption capacity of EO either increases at R.H. $49 \%$ or decreases at R.H. 97\%. If the diffusivity of EO molecules relative to water molecules increases then at comparable affinity of both sort of molecules win the more loosely molecules of EO, i.e. an absorption capacity of EO at R.H. 49\% relative to R.H. 97\% increases. The absorption capacity ratio of EO at $49 \%$ and $97 \%$ R.H. is approximately equally (Figure 4) if the relative water and EO diffusion coefficients (both coefficients relate to apparent diffusion coefficient of pure water at comparable conditions) are 0.666 and 19 independently of sort of EO and ligno-cellulosic materials, respectively. Due to this fact, an increase of EO diffusivity decreases of its 


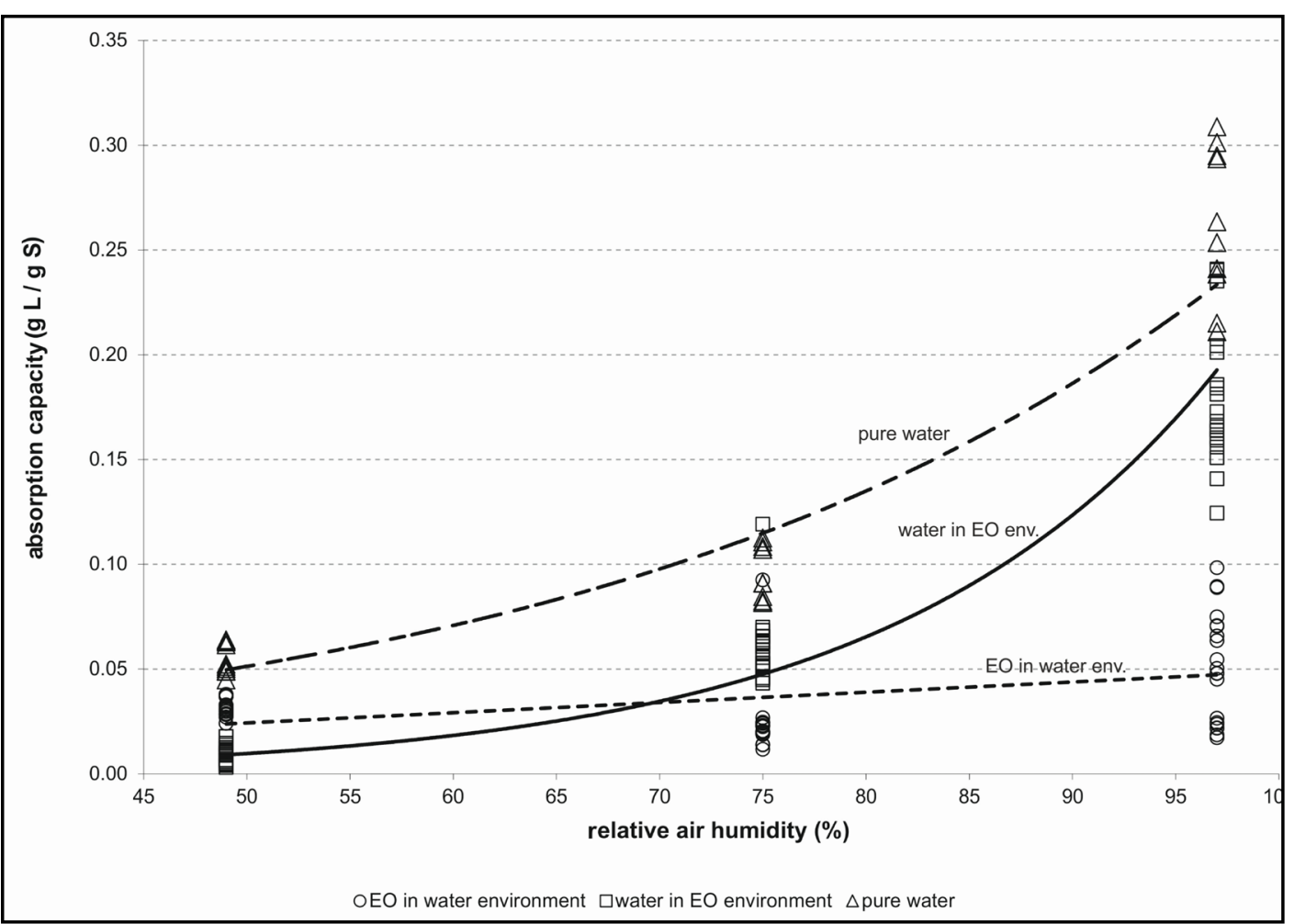

Figure 3. Absorption capacity of EO and water vs. relative air humidity. Note: Data are represented by 4 sorts of ligno-cellulosic materials and 6 kinds of EO vapours realized at $49 \%, 75 \%$ and $97 \%$ of R.H.

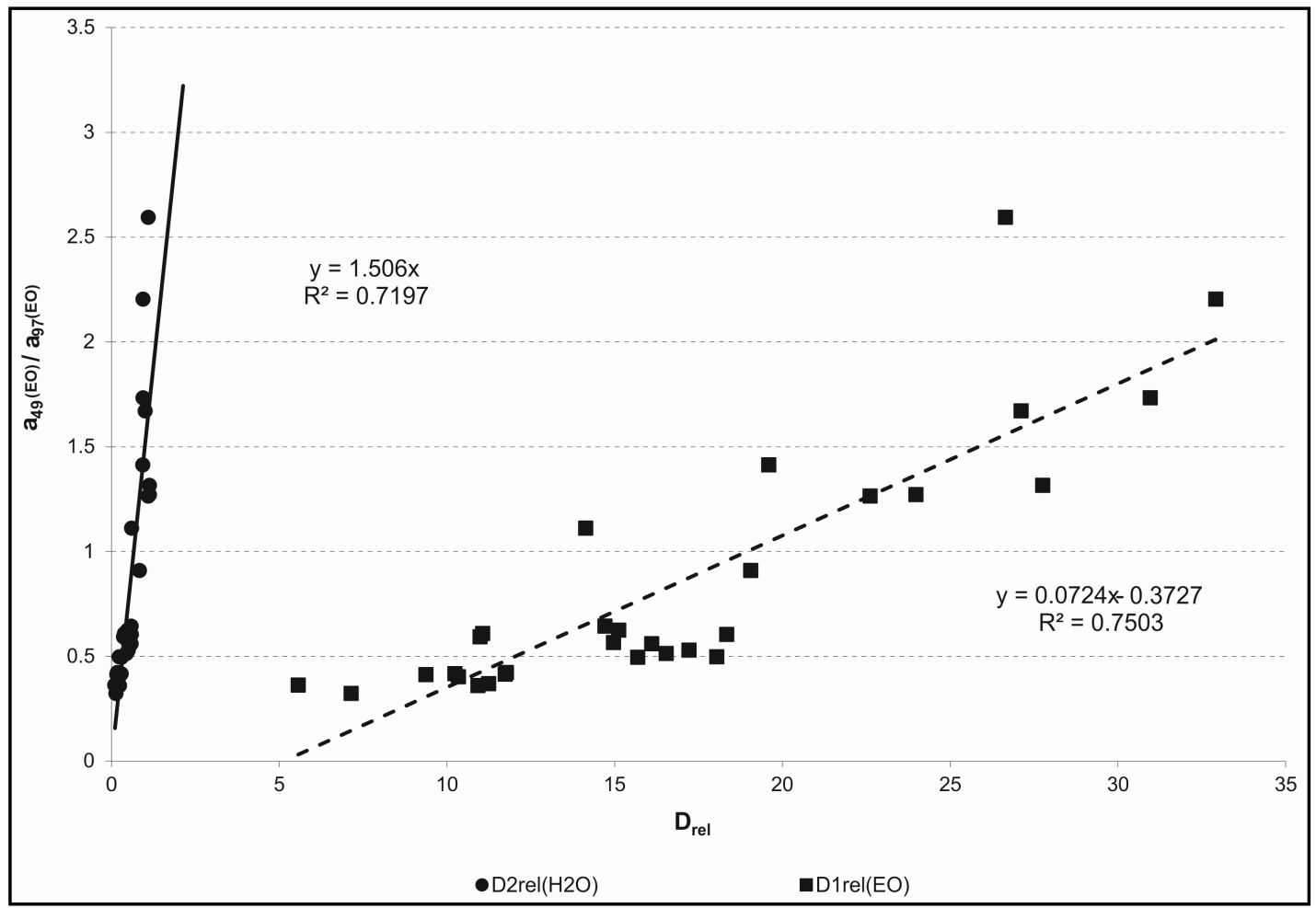

Figure 4. Absorption capacity ratio of EO vs. relative diffusion coefficient of water and EO (compared with apparent diffusion coefficient of pure water at comparable conditions). 
absorption capacity at $97 \%$ R.H. compared with water in markedly small extent. This behaviour has been really observed as documented the results in Figure 4. Being more competitive, an increase of absorption of EO at R.H. $97 \%$ relative to absorption capacity at R.H. $49 \%$ deals to decrease of EO diffusivity relative to water and vice versa as similar particularly for water. However, the diffusivity of water molecules is also influenced by sorption behaviour of EO molecules. A small increase of water diffusivity evokes high decrease in absorption capacity of EO molecules as documented Figure 4. Obviously, because the diffusivity of water molecules relatively deeply decreases at R.H. 97\%, the absorption capacity of EO also has to increase.

As schematically presented in Figure 5, competitive vapour absorption of water and other substances in porose material is resulted in a formation of stratified structure of fulfilled pores composed of water and EO condensed liquids and vapours of EO and water. With increasing of water absorption accompanied by dramatically decrease of its diffusivity with and without presence of EO vapours, a preferred diffusion of EO vapour molecules is evoked followed by their diffusion in appropriate not yet occupied pores. Additionally, due to following massive stepwise water condensation at R.H. 97\% in pores occupied by the EO vapour molecules, we have to expect a possible partially capture of these ones in hollow non-penetrable cavities of pores.

\section{Conclusions}

Common absorption, i.e. condensation, a process of water and EO substances, is predominantly controlled by extent of condensation of diffusing water and EO molecules with marginal influence of porose ligno-cellulosic

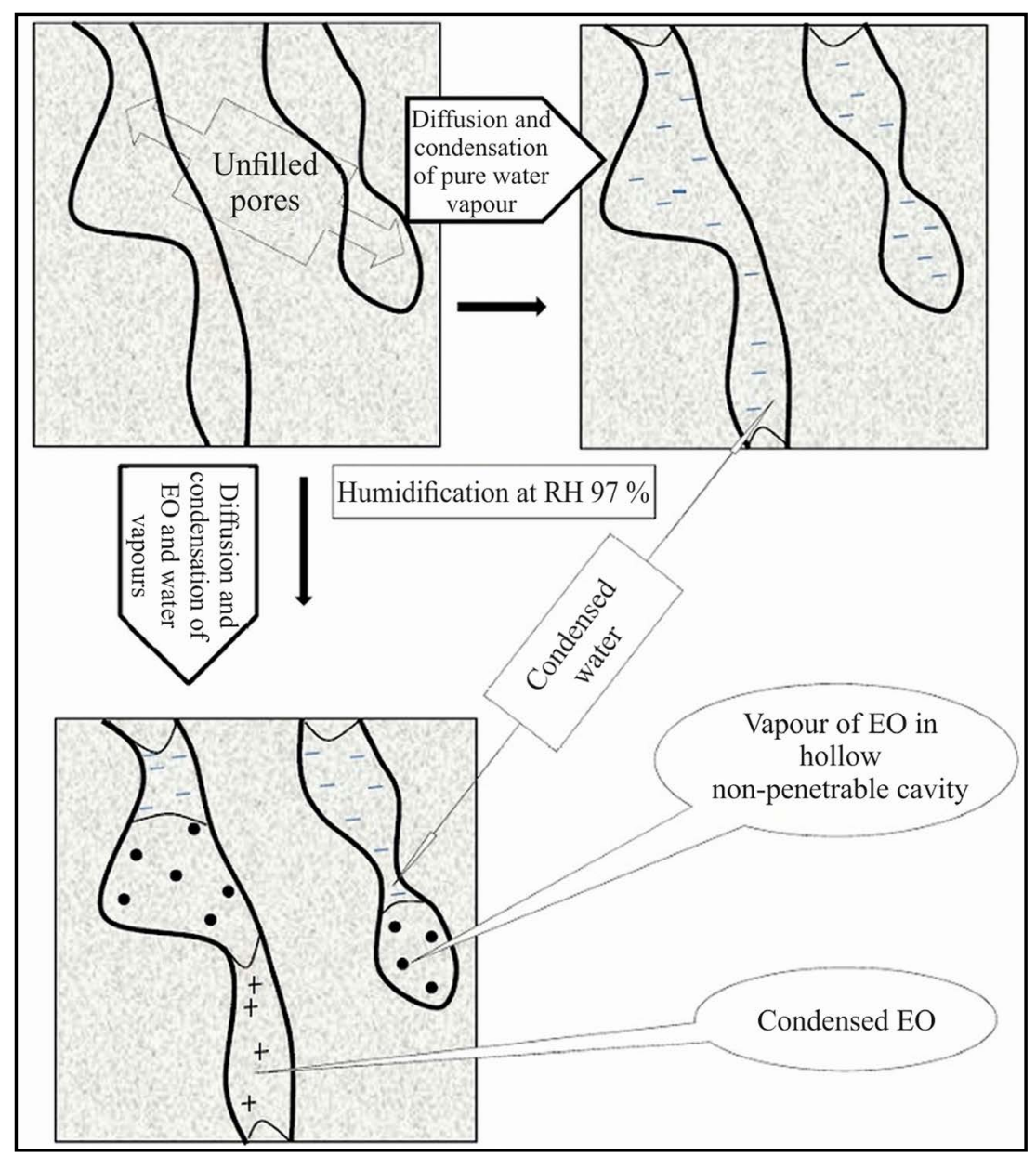

Figure 5. Schematically depiction of competitive vapour absorption of water and other substances in porose material resulting in a formation of stratified structure of fulfilled pores composed of water and EO condensed liquids and vapours of EO and water. 
matter and a sort of EO. The extent of absorption is given by concentration, i.e. by partial tension of condensed vapours predominantly water. With increase of absorption, the diffusion is depressed and vice versa. Due to this fact, diffusion of water molecules through porose system is usually slower in comparison with other molecules. As received results indicate, a presence of EO decreases paper web humidity with increasing influence in environment with high relative air humidity even so that total amount of all the common condensed components is lower than the total amount of condensed pure water vapour at comparable conditions.

By assumption of existence of two sorts of pores in porose material, i.e. two-end penetrable pores and oneend non-penetrable pores, a possible explanation exists. Fast diffusing EO molecules decrease the ability of water molecules condensed in all accessible pores particularly in the non-penetrable pores.

\section{Acknowledgements}

This work was supported by the Ministry of Culture of the Czech Republic under the Research Projects NAKI DF11P01OVV028.

\section{List of Symbols}

a: parameter Equation (1)—hygroscopicity or absorption capacity of the porous materials $(\operatorname{kg} L / \operatorname{kg} S)$

$b$ : parameter Equation (1) $\left(\right.$ day $\left.^{\mathrm{d}}\right)$

$d$ : parameter Equation (1) — the rate of steady-state adjustment

$d$ : relative dispersion (non-polar) part of surface tension (Table 1)

$D_{\text {rel }}$ : relative diffusion coefficient

$D_{\text {1rel }}(\mathrm{EO})$ : relative diffusion coefficient of EO

$D_{2 \text { rel }}\left(\mathrm{H}_{2} \mathrm{O}\right)$ : relative diffusion coefficient of water

$D_{\text {ap }}$ : apparent or pseudo diffusion coefficient $\left(\mathrm{m}^{2} \mathrm{~kg} S /\left(\mathrm{kg} L\right.\right.$ day $\left.\left.^{\mathrm{d}}\right)\right)$

$D_{\text {ap }}^{1}:\left(=d D_{\text {ap }}\right)$ standardized pseudo diffusion coefficient $\left(\mathrm{m}^{2} \mathrm{~kg} S /\left(\operatorname{kg} L\right.\right.$ day $\left.\left.{ }^{\mathrm{d}}\right)\right)$

I: effective maximal pore diameter fulfilled with condensed water at RH $49 \%(\mu \mathrm{m})$

$J$ : effective maximal pore diameter fulfilled with condensed water at RH $75 \%(\mu \mathrm{m})$

$K$ : effective maximal pore diameter fulfilled with condensed water at RH $97 \%(\mu \mathrm{m})$

$p^{-}$: relative anionactive polar part of surface tension of pore interface with air

$p$ : relative polar part of surface tension

$p^{+}$: relative cationactive polar part of surface tension of pore interface with air

$t$ : time of sample storage at given relative humidity (day)

$X_{\text {ra }}$ : half of sample thickness $(\mathrm{m})$

$Y$ : current moisture content $(\mathrm{kg} L / \mathrm{kg} S)$

$Y_{\mathrm{e}}$ : steady-state moisture content, equilibrium value $(\mathrm{kg} L / \mathrm{kg} S)$

$Y_{\mathrm{e}}(49 \%)$ : equilibrium humidity of paper strip at air of R.H. $97 \%(\mathrm{~kg} \mathrm{~L} / \mathrm{kg} \mathrm{S})$

$Y_{\mathrm{e}}(75 \%)$ : equilibrium humidity of paper strip at air of R.H. $75 \%(\mathrm{~kg} L / \mathrm{kg} S)$

$Y_{\mathrm{e}}(97 \%)$ : mequilibrium humidity of paper strip at air of R.H. 97\% $(\mathrm{kg} \mathrm{L} / \mathrm{kg} \mathrm{S})$

$Y_{\mathrm{i}}$ : initial moisture content $(\mathrm{kg} \mathrm{L} / \mathrm{kg} S)$

$\Delta Y$ : increment of moisture content $(\mathrm{kg} L / \mathrm{kg} S)$

$\Delta Y$ : increment of moisture content $(\mathrm{kg} L / \mathrm{kg} S)$

$\Delta Y_{\mathrm{e}}$ : steady-state increment of moisture, equilibrium value $(\mathrm{kg} L / \mathrm{kg} S)$

\section{Greek Letters}

$\varphi$ : relative humidity of air

$\gamma^{-}$: anionactive polar part of surface tension of pore interface with air $(\mathrm{mN} / \mathrm{m})$

$\gamma^{+}$: cationactive polar part of surface tension of pore interface with air $(\mathrm{mN} / \mathrm{m})$

$\gamma_{\mathrm{d}}$ : dispersion (non-polar) part of surface tension of pore interface with air $(\mathrm{mN} / \mathrm{m})$

$\gamma_{\mathrm{p}}$ : polar part of surface tension of pore interface with air $(\mathrm{mN} / \mathrm{m})$

$\gamma_{s}$ : surface tension of pore interface with air $(\mathrm{mN} / \mathrm{m})$

$\sigma_{\mathrm{T}}$ : adhesion tension of pore interface to water $(\mathrm{mN} / \mathrm{m})$

$\varepsilon_{\mathrm{i}}(49 \%)$ : wet sample porosity. i.e. the porosity fulfilled with condensed water-at R.H. $49 \%$ (\%)

$\varepsilon_{j}(75 \%)$ : wet sample porosity. i.e. the porosity fulfilled with condensed water-at R.H. 75\% (\%) 
$\varepsilon_{\mathrm{k}}(97 \%)$ : wet sample porosity. i.e. the porosity fulfilled with condensed water—at R.H. 97\% (\%) $\varepsilon$ : porosity (\%)

\section{References}

[1] Hammer, K.A., Carson, C.F. and Riley, T.V. (1999) Antimicrobial Activity of Essential Oils and Other Plant Extracts. Journal of Applied Microbiology, 86, 985-990. http://dx.doi.org/10.1046/j.1365-2672.1999.00780.x

[2] Survilienè, E., Valiuškaitè, A., Snieškienè, V. and Stankevičienè, A. (2009) Effect of Essential Oils on Fungi Isolated from Apples and Vegetables. Scientific Works of the Lithuanian Institute of Horticulture and Lithuanian University of Agriculture. Sodininkystè Ir Daržininkystè, 28, 227-234.

[3] Rakotonirainy, M.S. and Lavédrine, B. (2005) Screening for Antifungal Activity of Essential Oils and Related Compounds to Control the Biocontamination in Libraries and Archives Storage Areas. International Biodeterioration \& Biodegradation, 55, 141-147. http://dx.doi.org/10.1016/j.ibiod.2004.10.002

[4] Češek, B., Milichovský, M. and Potůček, F. (2011) Kinetics of Vapour Diffusion and Condensation in Natural Porous Cellulosic Fibre Web. ISRN Materials Science, 2011, 794306. http://dx.doi.org/10.5402/2011/794306

[5] Szycher, M. and Lee, S.J. (1992) Modern Wound Dressings: A Systematic Approach to Wound Healing. Journal of Biomaterials Applications, 7, 142-213. http://dx.doi.org/10.1177/088532829200700204

[6] Mcmillin, C.R. (1987) Characterization of Hexsyn, a Polyolefin Rubber. Journal of Biomaterials Applications, 2, 3-99. http://dx.doi.org/10.1177/088532828700200101

[7] Netravali, A.N. (2005) Biodegradable Natural Fiber Composites. In: Blackburn, R.S., Ed., Biodegradable and Sustainable Fibres, CRC Press Boca Raton, Cambridge, England, 271-309.

\section{Abbreviations}

DM: mixture $90 \%$ of spruce groundwood and $10 \%$ of MgBi-sulphite spruce bleached pulp

EO: essential oil(s)

L: liquid

R.H.: relative humidity

S: solid

Sa J: bleached sulphate softwood pulp

Sa L: bleached sulphate hardwood pulp

Si: MgBi-sulphite spruce bleached pulp 